\title{
Adequação de uma propriedade rural mineira ao Código Florestal Federal, Lei 12.651 de 2012
}

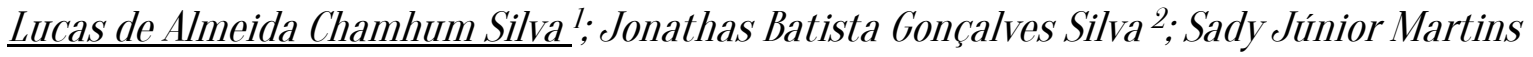 \\ Costa de Menezes ${ }^{3}$; Paulo Siqueira Júnior ${ }^{4}$ \\ $\underline{\text { lucas.almeida@engenharia.ufjf.br }}$
}

\begin{abstract}
1. Universidade Federal de Minas Gerais (UFMG) - Escola de Engenharia, Avenida Antônio Carlos, 6627,Belo Horizonte, Brasil.
2. Universidade Federal de Juiz de Fora (UFJF). Rua José Lourenco Kelmer, S/N, Juiz de Fora, Brasil.

3. Universidade Federal Rural do Rio de Janeiro (UFRRJ)- Instituto Três Rios, Avenida Prefeito Alberto da Silva Lavinas, 1847, Três Rios, Brasil. 4. Agconsult Consultoria Ambiental e Mineral Ltda., Avenida Doutor Paulo Japiassu Coelho, Cascatinha, 36033310 - Juiz de Fora, Brasil.
\end{abstract}

Histórico do Artigo:

Recebido: 22 de novembro de 2016

Aceito: 28 de junho de 2017

Publicado: 18 de julho de 2017

Resumo: Nas últimas décadas se intensificou o debate em torno dos aspectos social, ambiental e econômico da Lei 12.651 de 2012, que instituiu o Novo Código Florestal Federal. Visando contribuir com as discussões no presente trabalho avaliou-se a situação de uma pequena propriedade rural junto ao Novo Código Florestal Federal, 2012, em especial no que se refere às Áreas de Preservação Permanente (APP) e Áreas de Uso Restrito (AUR). A área de estudo possui 69,7 ha e está localizada no município de Juiz de Fora, na Zona da Mata Mineira. As bases de dados utilizadas neste trabalho consistem nas imagens de satélites RapidEye, disponibilizadas pelo Ministério do Meio Ambiente, e Google Earth, além de levantamento de campo realizado com GPS de Navegação. A manipulação dos dados foi realizada no ambiente de Sistema de Informação Geográfica ArcGIS for Desktop 10.2.1. Foi identificado na área de estudo AUR e APPs ao longo dos cursos d'água e ao redor de nascentes. As AURs mapeadas representam 12,31 ha, equivalente a 17,64\% da área total. As APPs de curso d'água e nascente somadas representam 19,42 ha, ou 27,83\% da área total. Verificou-se a necessidade de recomposição obrigatória nas APPs de, no mínimo, 6,85 ha para adequação da propriedade à legislação. Ademais, foram propostas medidas de manejo e ocupação do solo para a recomposição das áreas previstas.

Palavras-chave: Novo Código Florestal, Lei 12.651, Área de Preservação Permanente, Desmatamento.

\section{Suitability of a Brazilian land farm property to the Federal Forestry Code, 2012, Law 12.651}

\begin{abstract}
Law 12651/2012 has increased. Aiming to contribute with current discussions, this research evaluated the compliance of a small farm regarding the new Federal Forest Code in what concerns Permanent Preservation Areas (APP) and Restricted Use Areas (AUR). This study was performed in a 69.7 hectares area located in the southeast of Brazil, in the city of Juiz de Fora, Minas Gerais. RapidEye satellite images, provided by Brazilian Ministry of Environment, and Google Earth, were adopted as database. Furthermore, primary data was collected using navigation GPS. The database was manipulated in ArcGis Geographic Information System for Desktop 10.2.1. AUR and APP were identified in study area nearby watercourses and water sources. Identified AUR represented 12.31 ha, equivalent to $17.64 \%$ of total area. Watercourses and water sources, in total, represented 19.42 ha, meaning $27.83 \%$ of total area. Recovery of at least 6.85 ha is mandatory to comply with Brazilian legislation. Management and occupation guidelines were proposed to reach restoration of required areas.
\end{abstract}

Keywords: Federal Forestry Code, Law 12.651, Permanent Preservation Area, Deforestation. 


\title{
Adecuación de una propiedad rural brasileña al Código Forestal Federal, Ley 12.651 de 2012
}

\begin{abstract}
Resumen: En las últimas décadas se há intensificado el debate en torno a los aspectos sociales, ambientales y económicos de la Ley 12.651 de 2012, la cual instituyó el nuevo Código Forestal Federal Brasilero. Con el fin de contribuir a esta discusión, el presente trabajo evaluó la situación de una pequeña propiedad rural de acuerdo con el Nuevo Código Forestal Federal, 2012, en especial a lo que se refiere a las Áreas de Preservación Permanente (APP) y Áreas de Uso Restringido (AUR). El área de estudio tiene una extensión de 69,7 ha y está localizada en el municipio de Juiz de Fora, en la Zona da Mata Mineira. Las bases de datos utilizadas en este trabajo consisten en las imágenes de satélites RapidEve, suministradas por el Ministerio del Medio Ambiente y Google Earth, además del levantamiento de campo realizado con GPS de Navegación. El procesamiento de los datos fue realizado en el ambiente del Sistema de Información Geográfica ArcGIS para escritorio 10.2.1. Fueron identificadas en el área de estudio AUR y APPs a lo largo de los cuerpos de agua y alrededor de nacimientos. Las AURs mapeadas representan 12,31 ha, equivalentes al 17,64\% del área total. Las APPs del cuerpo de agua y nacimientos, sumadas, representan 19,42 ha o 27,83\% del área total. Se verificó la necesidad de recomposición obligatoria de las APPs de, por lo menos, 6,85 ha para adecuar la propiedad a la legislación. Adicionalmente, fueron propuestas medidas de gestión y ocupación del suelo para la restauración de las áreas requeridas.
\end{abstract}

Palabras clave: Código Forestal Federal, Ley 12.651, Áreas de Preservación Permanente, Deforestación.

\section{INTRODUÇÃ0}

As discussões acerca das questões ambientais têm se intensificado nas últimas décadas por diversas razões, entre elas o desmatamento. Segundo dados da Food and Agriculture Organization of the United Nations - FA0, entre os anos de 1990 a 2000 e 2000 a 2010, foi observado em todo o território brasileiro uma taxa de desmatamento anual de $28.900 \mathrm{~km}^{2} \mathrm{e}$ $26.420 \mathrm{~km}^{2}$, respectivamente $(\mathrm{FA0}, 2011)$. Embora a maior parte da área desmatada esteja compreendida no bioma Amazônico - aproximadamente 63\% do total (INPE, 2014), destaca-se 0 fato do bioma Mata Atlântica, terceiro maior bioma brasileiro, continuar sofrendo fortes pressões com a supressão de vegetação florestal nativa, fato que evidencia o descumprimento da Lei 11.428 de 2006, também conhecida como Lei da Mata Atlântica, que visa à proteção do bioma em questão.

Dessa forma, da área total de $1.309 .736 \mathrm{~km}^{2}$ prevista no Mapa da Área de Aplicação da Lei da Mata Atlântica, observa-se que em 2012, somados os fragmentos de floresta nativa superior a três hectares, restam apenas $164.069 \mathrm{~km}^{2}$, o equivalente a $12,5 \%$ da área original (FUNDAÇ̃̃o SOS MATA ATLÂNTICA; INPE, 2014). De acordo com a Fundação SOS Mata Atlântica (2014), em torno de 72\% da população brasileira reside neste bioma, cuja área remanescente se estende por aproximadamente 13\% da área total do país (IBGE, 2004). 
Segundo Young (2006), a perda de áreas florestadas, em particular as de Mata Atlântica, está historicamente relacionada à forma de ocupação territorial e ao modo de exploração do território estabelecidos no Brasil desde o início da era colonial. Neste período, as principais atividades econômicas do Brasil estiveram relacionadas à extração dos recursos naturais, como a extração do Pau-Brasil, os ciclos da cana-de-açúcar, a mineração de ouro, cultura do cafeeiro e a pecuária até o mercado de commodities estabelecido no início do século XXI, o qual compreende as atividades de extração mineral (desde de minério de ferro até o petróleo), agrossilvipastoris (cultivo de soja, milho, pecuária), dentre outras.

No que se refere ao cenário de agricultura e pecuária o processo de conversão de área florestada em pastagens e lavouras é baseado no argumento de que é necessário ampliar a área produtiva visando ao desenvolvimento econômico e aumento de qualidade de vida da população rural. Porém, o que se observa na realidade, é que não existe uma relação de causalidade entre desmatamento e melhora das condições de vida da população rural (SANTOS, 2004).

Um exemplo típico das pressões antrópicas sobre o bioma de Mata Atlântica é representado pelo Estado de Minas Gerais. Segundo a Fundação SOS Mata Atlântica e INPE (2015), entre os anos de 1985 a 2013 houve um decréscimo da cobertura vegetal de aproximadamente $3.703 \mathrm{~km}^{2}$, o que corresponde a $20 \%$ do total de área desmatada em todo 0 bioma no mesmo período - $18.509 \mathrm{~km}^{2}$. Conforme monitoramento da vegetação nativa de Minas Gerais realizado por Carvalho, Scolforo e Cavalcanti (2009), no período de 2005 a 2007 aproximadamente $60 \%$ das áreas desflorestadas foram convertidas em pastagens e lavouras. Estes mesmo autores ressaltam que o período avaliado não retrata o histórico de conversão do uso do solo em Minas Gerais, porém apresenta a tendência de ocupação geral do solo no estado.

Dessa forma, visando à proteção dos biomas brasileiros e a regulação das atividades desenvolvidas nos mesmos, diversos dispositivos legais foram elaborados e atualizados ao longo dos anos. Entre eles pode-se citar: Decreto 23.723 de 1934, que estabeleceu o primeiro Código Florestal; Lei 4.771 de 1965, que consistiu na atualização do Código Florestal de 1934; Lei 6.938 de 1981, marco no estabelecimento da Política Nacional de Meio Ambiente; Lei 9.605 de 1998, que determina sanções penais e administrativas derivadas de condutas e atividades lesivas ao meio ambiente; Constituição da República Federativa do Brasil, a qual dedica um capítulo à proteção do meio ambiente; entre outros. 
Neste estudo foram abordados especificamente os aspectos relacionados à Lei 12.651/2012, com foco nas Áreas de Preservação Permanente (APP), Áreas de Uso Restrito (AUR) e Reserva Legal (RL). De acordo com definições previstas na lei a APP compreende a área protegida, coberta ou não por vegetação nativa, com a função ambiental de preservar os recursos hídricos, a paisagem, a estabilidade geológica e a biodiversidade, facilitar o fluxo gênico de fauna e flora, proteger o solo e assegurar o bem-estar das populações humanas. Já as AUR são aquelas com declividade entre 25 e $45^{\circ}$. Por fim, a RL consiste na área localizada no interior de uma propriedade ou posse rural, delimitada nos termos do art. 12 desta lei, com a função de assegurar o uso econômico de modo sustentável dos recursos naturais do imóvel rural, auxiliar a conservação e a reabilitação dos processos ecológicos e promover a conservação da biodiversidade, bem como o abrigo e a proteção de fauna silvestre e da flora nativa (BRASIL, 2012).

Diante de inúmeras normas e especificidades regionais verificam-se situações de conflito de uso da terra em áreas legalmente protegidas, notadamente para implementação e desenvolvimento de atividades agrossilvipastoris (OKUYAMA et al., 2012; ZANATA et al., 2012; VALLE JÚNIOR et al., 2010; SANTOS; MARTINS, 2010; NASCIMENT0 et al., 2005). Entre os entraves para a aplicação da legislação estão: políticas públicas de educação e orientação aos produtores, especialmente em pequenas propriedades rurais, que em geral não têm receita suficiente para suprir as demandas por regularização ambiental da propriedade; iniciativas isoladas de incentivo e apoio à recuperação de áreas sensíveis; dificuldade de se promover efetiva fiscalização ambiental em um país de dimensões continentais; complexidade da legislação ambiental; pressões econômicas; cultura predatória dos recursos naturais, entre outros.

Nesse sentido, destaca-se a potencialidade das geotecnologias como auxílio ao monitoramento, planejamento e regularização ambiental. Assim, em virtude das dificuldades encontradas para a adequação das propriedades rurais ao Novo Código Florestal, torna-se necessário a realização de estudos que enfoquem a utilização de geotecnologias associadas à legislação vigente, a fim de otimizar o processo de regularização dos produtores rurais. Diante do exposto, o trabalho desenvolvido consiste em avaliar a situação de uma pequena propriedade rural da Zona da Mata Mineira e dispor propostas de adequação junto à Lei 12.651 de 2012 - Novo Código Florestal Federal. 


\section{MATERIAL E MÉTODOS}

Este estudo foi realizado em uma pequena propriedade rural denominada Sítio Bela Vista, no período de abril de 2014 a julho de 2015. A propriedade situa-se na zona rural do município de Juiz de Fora - MG, a uma distância de aproximadamente $42 \mathrm{~km}$ do centro urbano, com coordenadas geográficas $21^{\circ} 57^{\prime} 06^{\prime \prime}$ de latitude sul Gw e $43^{\circ} 31^{\prime} 52^{\prime \prime}$ de longitude oeste Gw, datum WGS84. 0 relevo do local é predominante ondulado a fortemente ondulado (CPRM, 2013). De acordo com o registro do imóvel, a propriedade possui 69,7 ha. Considerando-se que, para o município de Juiz de Fora, o módulo fiscal equivale a 24 ha, verifica-se que esta propriedade é classificada, segundo o Paragrafo único do artigo $3^{\circ}$ do Código Florestal, como pequena propriedade rural - até 4 módulos fiscais.

A principal atividade desenvolvida na propriedade é a bovinocultura de leite, em sistema semiextensivo, ou seja, animais criados a pasto com suplementação volumosa na época de menor crescimento do pasto. As suplementações disponíveis na propriedade são a capineira, formada por capim Napier, e a cana-de-açúcar. Ao percorrer o local verificou-se a presença de cursos d'água, nascentes, fragmentos de remanescentes florestais, assim como áreas degradadas e outras em estágio de regeneração natural.

As informações de interesse a serem identificadas no presente trabalho abrangem as Áreas de Preservação Permanente, Áreas de Uso Restrito, remanescentes florestais, visando à locação da Reserva Legal, áreas de cultivo permanente e as divisas da propriedade rural. Segundo o Novo Código Florestal, com o advento do Cadastro Ambiental Rural - CAR a averbação da Reserva Legal em cartório foi dispensada, não sendo prevista na lei a precisão mínima dos vértices da poligonal referente a delimitação da Reserva Legal. Assim, foram empregados três métodos de levantamento para posterior comparação entre eles. 0 primeiro se deu por meio do GPS de Navegação, modelo Garmin eTrex@ 30, cuja precisão é em torno de 15 m (IBGE, 2008). 0 segundo método consistiu na utilização de interpretação de imagens do satélite RapidEye para digitalização em ambiente SIG das feições ambientais do imóvel. Tais imagens foram oriundas da base de dados disponibilizada pelo Ministério do Meio Ambiente para a realização do CAR e a data de tomada das cenas é referente ao mês de Novembro de 2013, sendo estas já obtidas ortorretificadas e com resolução de $5 \mathrm{~m}$. Já o terceiro método consistiu na utilização de interpretação de imagens do satélite Digital Globe disponibilizadas em Julho de 2014 pelo Software Google Earth. A escolha destas imagens deve-se ao fato de ser uma base de dados 
gratuita e amplamente utilizada. Deve-se ressaltar que nenhum dos métodos descritos atendem aos requisitos para fins de regularização fundiária, visto que este propósito é regulado através da Norma Técnica para Georreferenciamento de Imóveis Rurais - $3^{\circ}$ edição, do Instituto Nacional de Colonização e Reforma Agrária. Por fim, a manipulação dos dados foi realizada utilizando o software ArcGis for Desktop 10.2.1. A Figura 1 ilustra as imagens da área de estudo tomadas pelos satélites RapidEye (A) e Google Earth (B).

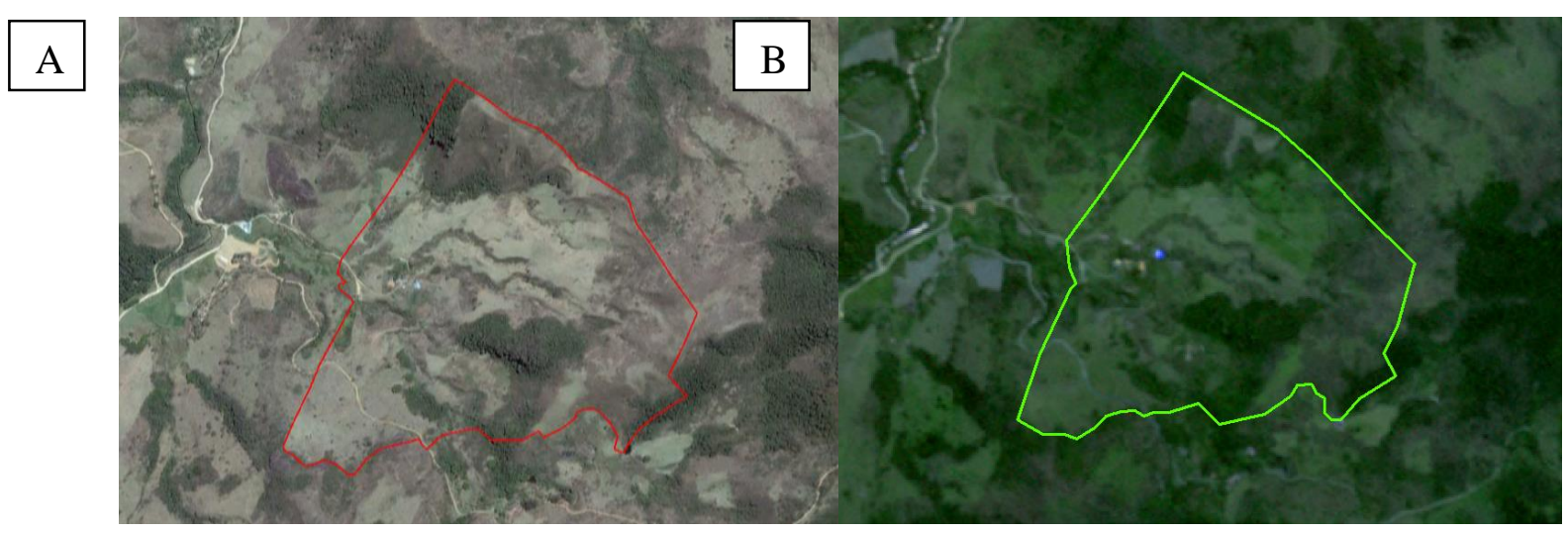

Figura 1. Imagens da área de estudo - RapidEye (A) e Google Earth (B) Fonte: 0s Autores, 2015.

A avaliação dos métodos empregados foi feita de duas formas, a primeira baseada na comparação entre as áreas das feições delimitadas por cada método e a segunda por meio de comparação visual entre as imagens utilizadas em cada método. Na Primeira Análise foi avaliada a diferença entre a área total obtida em cada método e a área indicada no registro do imóvel, tida como referência. Esta diferença de área verificada entre cada um dos três métodos em relação a área de registro é influenciada por uma série de fatores como a incerteza de precisão do GPS de navegação (método 1), a resolução espacial das imagens (métodos 2 e 3) e arbitrariedade da interpretação visual do pesquisador no processo de digitalização. Na segunda análise foi realizado um comparativo visual das imagens disponibilizadas pelo Google Earth e Ministério do Meio Ambiente (RapidEye), avaliando-se a qualidade da imagem através da identificação de objetos, feições e classes de uso de solo. Ressalta-se que a interpretação e comparação das imagens está aliada ao conhecimento de campo das áreas mapeadas por parte do pesquisador. 
Para realizar a delimitação das Áreas de Preservação Permanente - APP foram analisados a existência de cursos d'água, nascentes, topos de morro e encostas ou parte destas com declividade superior a $45^{\circ}$. Adicionalmente, analisou-se a incidência de áreas de uso restrito. $0 \mathrm{~s}$ aspectos relacionados ao relevo foram analisados com base no Modelo Digital de Elevação ASTER GDEM, cuja resolução espacial é de 30 m (ASTER GDEM, 2015). A manipulação seguiu metodologia apresentada por Oliveira e Fernandes Filho (2013).

A propriedade em estudo é enquadrada, segundo o Novo Código Florestal, como de pequeno porte e com áreas de uso consolidado, ou seja, área do imóvel rural com ocupação antrópica preexistente a 22 de julho de 2008, com edificações, benfeitorias ou atividades agrossilvipastoris, admitida, neste último caso, a adoção do regime de pousio (BRASIL, 2012). Assim, as APPs e faixas de recomposição seguem as delimitações apresentadas na Tabela 1. Além das APPs delimitou-se as Áreas de Uso Restritivo.

Tabela 1 - Faixas de Áreas de Preservação Permanente e de recomposição de acordo com cada feição

\begin{tabular}{|c|c|c|}
\hline FEIÇÃO & $\begin{array}{l}\text { ÁREA DE PRESERVAÇÃ0 } \\
\text { PERMANENTE }\end{array}$ & $\begin{array}{c}\text { FAIXA DE } \\
\text { RECOMPOSIÇÃO }\end{array}$ \\
\hline $\begin{array}{c}\text { Curso d'água natural perene e } \\
\text { intermitente de até } 10 \mathrm{~m} \text { de } \\
\text { largura }\end{array}$ & $\begin{array}{l}\text { Mínimo de } 30 \mathrm{~m} \text { em faixas } \\
\text { marginais, desde a borda da calha } \\
\text { do leito regular }\end{array}$ & $\begin{array}{l}15 \mathrm{~m} \text {, contados } \\
\text { da borda da } \\
\text { calha do leito } \\
\text { regular }\end{array}$ \\
\hline $\begin{array}{l}\text { Entorno de nascentes e dos } \\
\text { olhos d'água perenes }\end{array}$ & Raio de $50 \mathrm{~m}$ & $\begin{array}{l}\text { Raio mínimo de } \\
15 \mathrm{~m}\end{array}$ \\
\hline $\begin{array}{c}\text { Topo de morros, montanhas e } \\
\text { serras, com altura mínima de } \\
100 \text { m e inclinação média maior } \\
\text { que } 25^{\circ}\end{array}$ & $\begin{array}{l}\text { Áreas delimitadas a partir de } 2 / 3 \\
\text { da altura em relação à base, sendo } \\
\text { esta definida pelo plano } \\
\text { horizontal determinado por } \\
\text { planície, espelho d'água ou ponto } \\
\text { de sela mais próximo da elevação }\end{array}$ & Não Aplicável \\
\hline Encostas & $\begin{array}{l}\text { Encostas ou parte destas com } \\
\text { declividade superior a } 45^{\circ}\end{array}$ & Não Aplicável \\
\hline
\end{tabular}

Fonte: Adaptado de Brasil, 2012. 


\section{RESULTADOS E DISCUSSÃ0}

0 comparativo entre as áreas obtidas nos três levantamentos e a área de referência pode ser observado na Tabela 2.

Tabela 2 - Comparativo de área entre os levantamentos realizados no estudo e o levantamento de referência

\begin{tabular}{|ccc|}
\hline LEVANTAMENT0 & ÁREA (ha) & ERR0 (\%) \\
\hline Referência & 69,7665 & - \\
\hline GPS de Navegação & 71,5168 & 2,51 \\
\hline Google Earth & 71,2352 & 2,11 \\
\hline RapidEye & 75,0408 & 7,56 \\
\hline
\end{tabular}

Fonte: 0s Autores, 2015.

Analisando os resultados da Tabela 2 verifica-se que o levantamento realizado com GPS de Navegação se aproxima substancialmente do levantamento realizado por meio da digitalização do Google Earth. Este fato pode ter ocorrido pois na digitalização do Google Earth foi possível identificar os pontos coletados em campo, tornando-os o mais próximo possível. Tal fato não ocorreu com a imagem do RapidEye, na qual a dificuldade em identificar e correlacionar os objetos e feições verificados em campo com os observados na imagem do satélite, em especial aqueles que determinam as divisas da propriedade, como cercas, cursos d’água, culminou em uma diferença superior às demais. Vale destacar que cada método empregado possui suas limitações de aplicação, que devem ser avaliadas de acordo com cada área. 0 levantamento com GPS de Navegação permite a identificação de nascentes e corpos d'água que são imperceptíveis nas imagens de satélite devido à região do entorno - por exemplo, em áreas densamente florestadas, dimensão dos corpos d'água e resolução da imagem disponível para o local. Por outro lado, no levantamento de campo o operador do equipamento assume o risco de incidentes, tendo limitações devido às condições do tempo e locais inacessíveis.

As análises subsequentes foram realizadas tomando-se como divisa da propriedade 0 polígono gerado através da digitalização do Google Earth, visto que o erro obtido foi o menor entre os métodos avaliados. Primeiramente, avaliou-se a situação da propriedade no ano de 2015 
com base nos parâmetros relacionados às APPs e Reserva Legal. 0 resultado pode ser observado conforme ilustrado na Figura 2. Em seguida, ao se aplicar as metodologias de delimitação das APPs e Área de Uso Restrito (AUR) obteve-se o mapa apresentado na Figura 3.

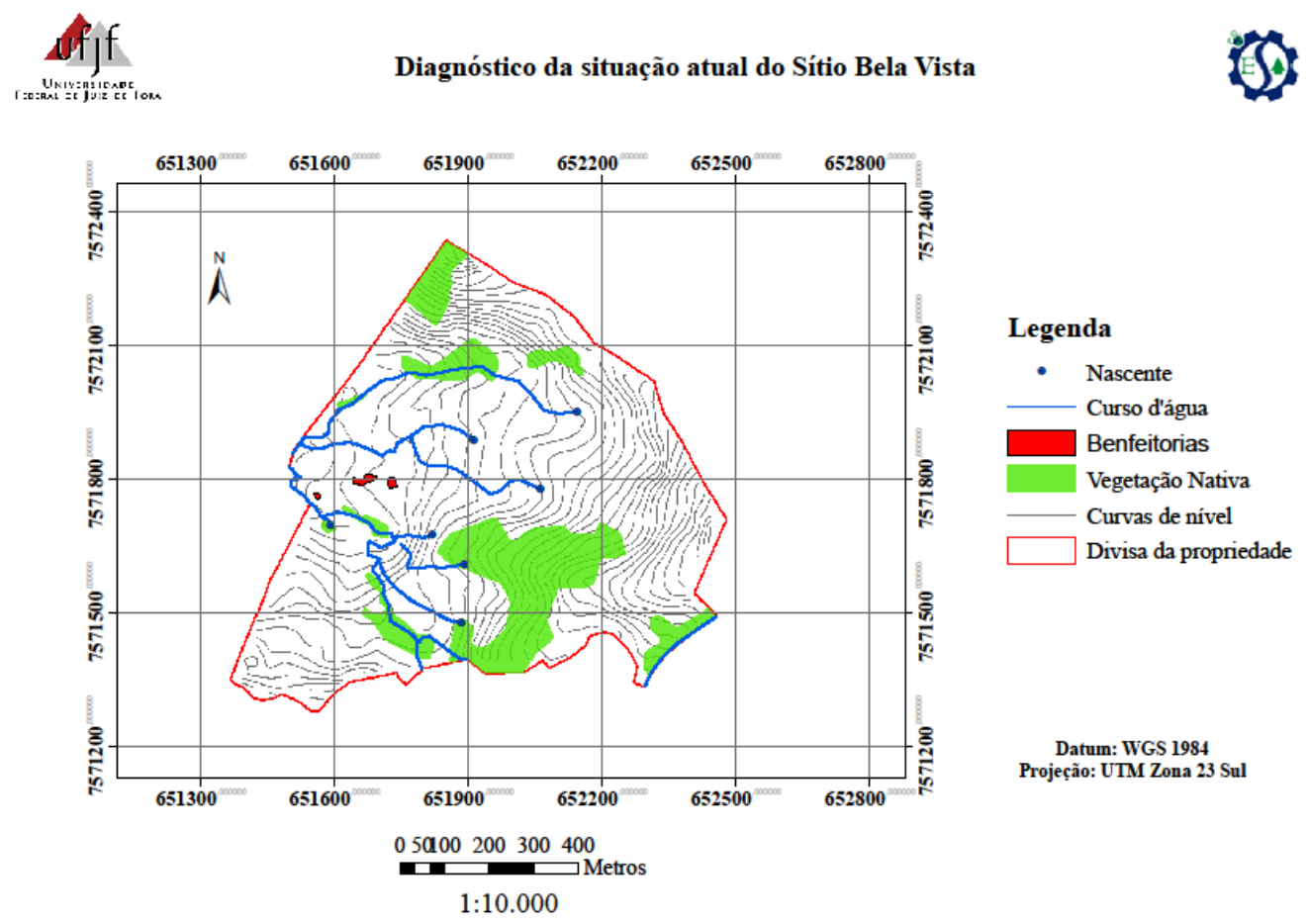

Figura 2. Diagnóstico da situação atual da propriedade rural Fonte: 0s Autores, 2015.

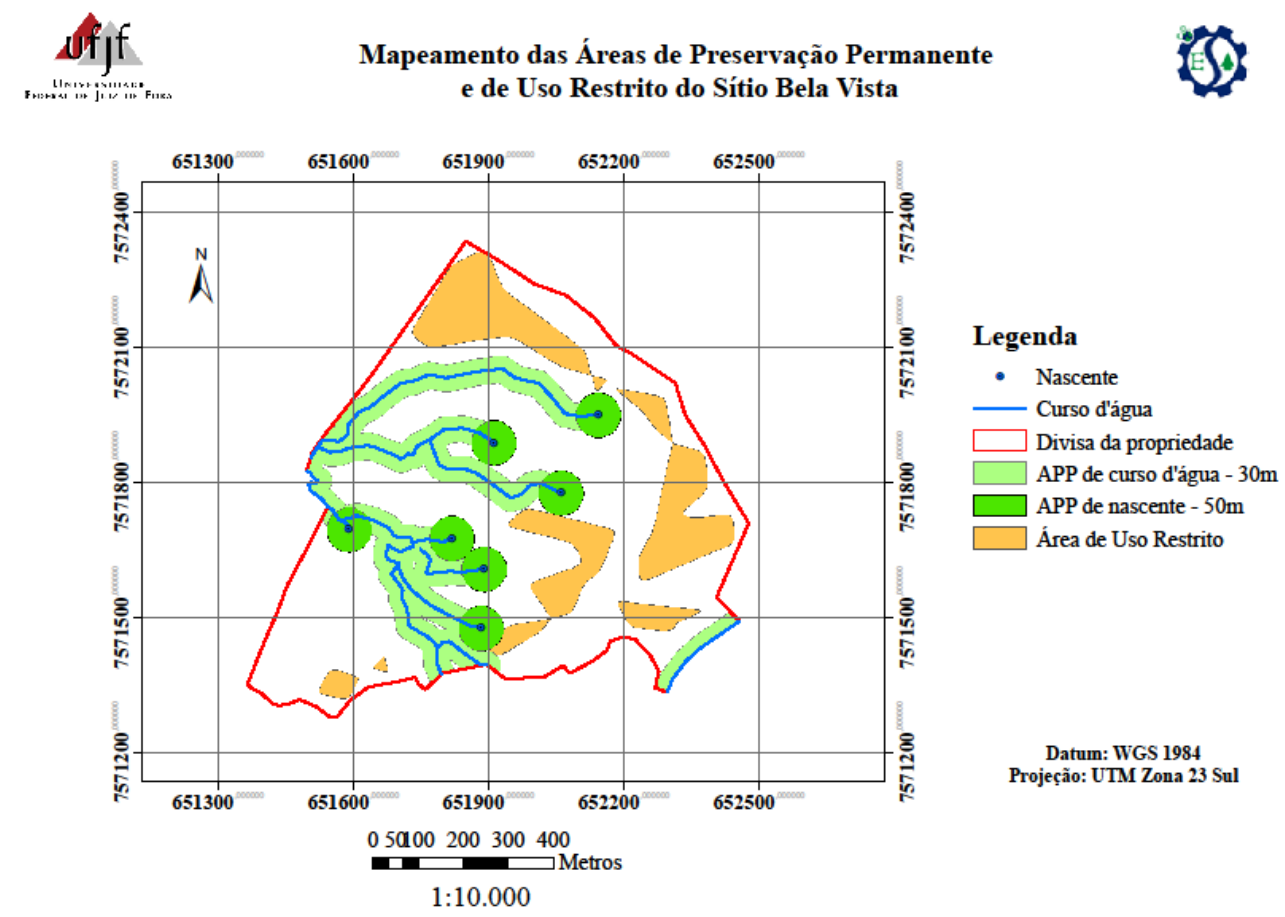

Figura 3. Mapeamento das APPs e AUR existentes na área de estudo Fonte: 0s Autores, 2015. 
As áreas mapeadas na propriedade em estudo foram as APPs de curso d'água e nascentes e AUR. Como pode-se constatar, a propriedade rural não se enquadrou nos critérios de APPs de topo de morro e APPs em encostas ou parte destas com declividade superior a $45^{\circ}$. A não observância das APPs de topo de morro deve-se ao fato de que na área de estudo, a diferença de cotas entre o topo do morro e sua base - plano horizontal determinado por planície, espelho d'água ou cota do ponto de sela mais próximo, é inferior aos 100m definidos no Novo Código Florestal, seguindo o conceito do "Ponto de Sela" o qual foi verificado a sua inexistência para esta área em estudo.

Conforme apresentado na Tabela 3 as APPs de curso d'água e nascente ocupam 13,94 ha e 5,48 ha, respectivamente, totalizando 19,42 ha de APPs, o que representa 27,83\% da área total do imóvel. Ademais, as AUR - declividade entre 25 e $45^{\circ}$ totalizam 12,31 ha, ou seja, 17,64\% da área total. Considerando o somatório destas três classes de áreas observa-se que 31,73 ha, aproximadamente $46 \%$ da área total da propriedade, possuem algum tipo de restrição de uso do solo.

Tabela 3 - Áreas de Preservação Permanente e Uso Restrito baseadas nas faixas definidas na Lei 12.651 de 2012, o Novo Código Florestal

\begin{tabular}{ccc}
\hline CLASSE & FAIXA APLICÁVEL & ÁREA MAPEADA (ha) \\
\hline APP de curso d'água & $30 \mathrm{~m}$ & 13,94 \\
APP de nascente & $50 \mathrm{~m}$ & 5,48 \\
Área de Uso Restrito & $25^{\circ}$ a $45^{\circ}$ & 12,31 \\
\hline
\end{tabular}

Fonte: Os Autores, 2015.

Na Figura 4 são apresentados os fragmentos florestais existentes nas APPs. Analisando a distribuição espacial da vegetação verifica-se que, tanto as APPs de curso d'água quanto de nascente, não possuem a cobertura vegetal prevista. 


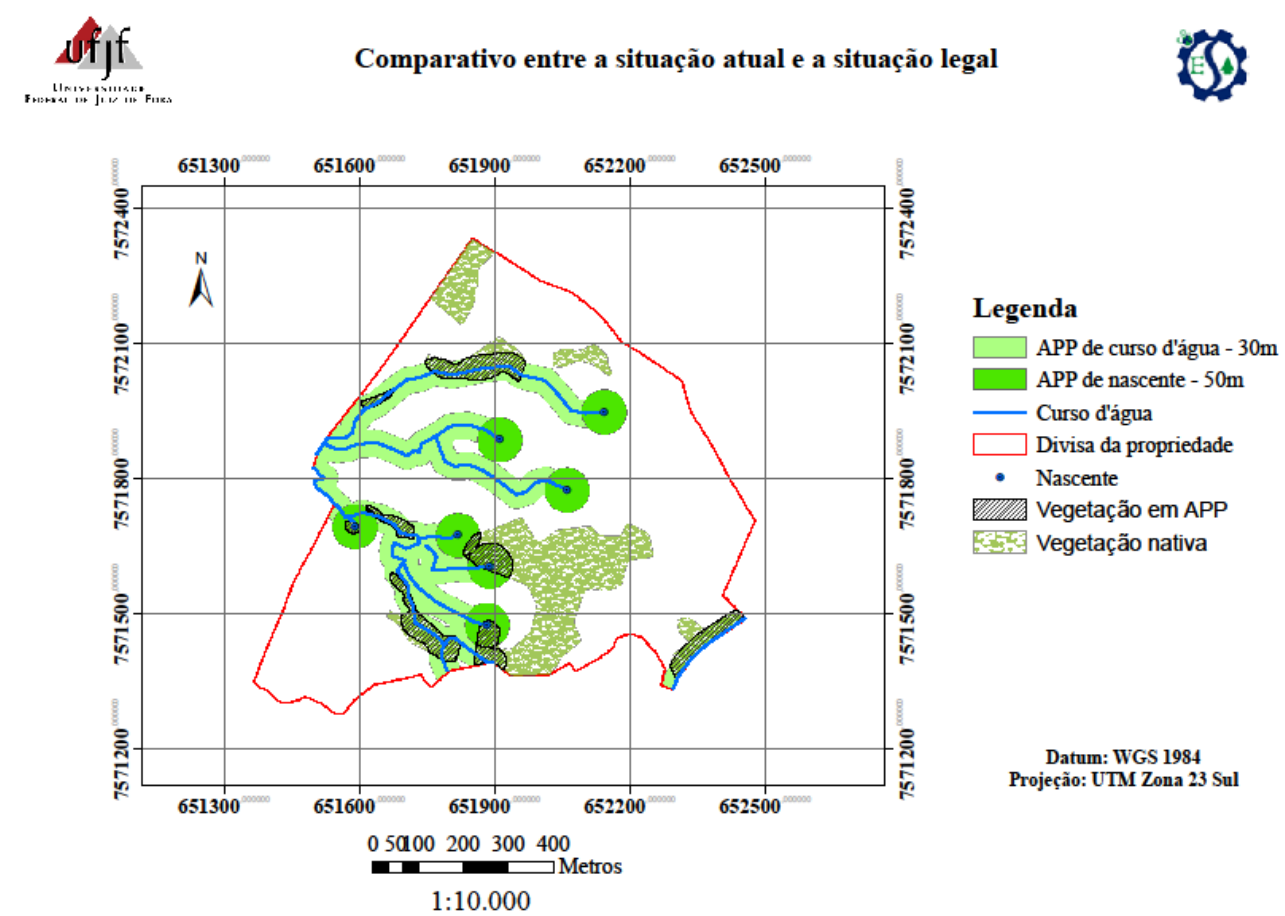

Figura 4. Mapa comparativo da situação atual e situação legal das APPs de nascente e curso d'água

Fonte: 0s Autores, 2015.

A área da vegetada contida nos polígonos de APPs, assim como o déficit de vegetação pode ser observada na Tabela 4. Este déficit de vegetação, somado ao uso atual do solo na forma de pastagem, torna estas áreas vulneráveis à degradação devido, por exemplo, ao pisoteio de animais e exposição do solo aos agentes erosivos..

Tabela 4 - Correlação entre área de APP e vegetação nativa existente nestas áreas

\begin{tabular}{cccccc}
\hline CLASSE DE APP & $\begin{array}{c}\text { FAIXA } \\
\text { APLICÁVEL }\end{array}$ & $\begin{array}{c}\text { ÁREA MAPEADA } \\
\text { (ha) }\end{array}$ & $\begin{array}{c}\text { VEGETAÇÃ0 ATUAL } \\
\text { EM APP (ha) }\end{array}$ & $\begin{array}{c}\text { DÉFICIT } \\
\text { (\%) }\end{array}$ \\
\hline Curso d'água & $30 \mathrm{~m}$ & 13,94 & 3,02 & 78,34 \\
Nascente & $50 \mathrm{~m}$ & 5,48 & 0,90 & 83,58 \\
\hline
\end{tabular}

Fonte: Os Autores, 2015.

0 cenário de recomposição obrigatória de vegetação nativa pode ser observado na Figura 5. Vale ressaltar que embora as faixas de recomposição apresentadas sejam de $15 \mathrm{~m}$ para nascentes e cursos d'água de até $10 \mathrm{~m}$ de largura entre as margens, as APPs continuam sendo aquelas apresentadas anteriormente, ou seja, 30 e $50 \mathrm{~m}$, respectivamente. A distribuição das 
áreas vegetadas inseridas nas faixas de recomposição obrigatória pode ser observada na Tabela 5.

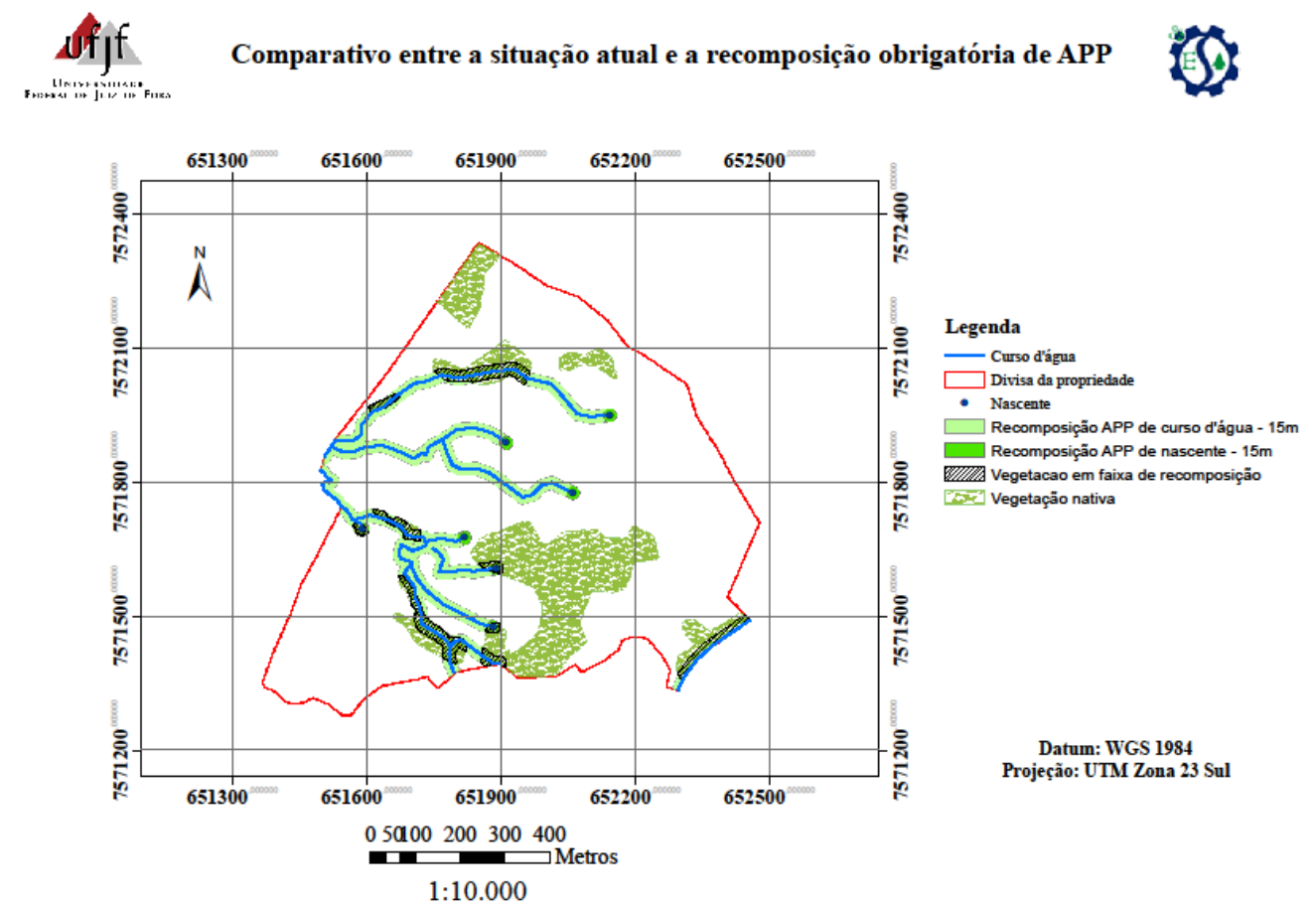

Figura 5. Mapa de disposição das faixas de recomposição obrigatória em APPS Fonte: 0s Autores, 2015.

Tabela 5 - Diagnóstico da situação atual nas faixas de recomposição obrigatória em APPs

\begin{tabular}{cccccc}
\hline & $\begin{array}{c}\text { FAIXA DE } \\
\text { RECOMPOSI- } \\
\text { ÇÃ0 } \\
\text { 0BRIGATÓRIA }\end{array}$ & $\begin{array}{c}\text { ÁREA DE } \\
\text { RECOMPOSIÇÃ0 } \\
\text { MAPEADA (ha) }\end{array}$ & $\begin{array}{c}\text { VEGETAÇÃ0 ATUAL } \\
\text { NA FAIXA DE } \\
\text { RECOMPOSIÇÃ0 } \\
\text { (ha) }\end{array}$ & $\begin{array}{c}\text { DÉFICIT } \\
\text { (\%) }\end{array}$ & $\begin{array}{c}\text { RECOMPOSI- } \\
\text { ÇA MÍNIMA } \\
\text { (ha) }\end{array}$ \\
\hline $\begin{array}{c}\text { APP de } \\
\text { curso } \\
\text { d'água } \\
\begin{array}{c}\text { APP } \\
\text { nascente }\end{array}\end{array}$ & $15 \mathrm{~m}$ & 8,50 & 1,97 & 76,82 & 6,53 \\
\hline
\end{tabular}

Fonte: 0s Autores, 2015.

Assim, considerando as APPs de nascentes e cursos d'água verifica-se a necessidade de recomposição mínima de 6,85 ha, aproximadamente 10\% da área total do imóvel. 
Em estudo realizado na micro bacia hidrográfica do Rio Preto, no estado de Espírito Santo, Celin Filho (2014) identificou a ocorrência de aproximadamente 10\% de APPs em relação à área total da micro bacia. Na análise do uso e ocupação do solo o autor observou que em torno de 60\% das APPs eram constituídas de floresta natural, enquanto os usos agrossilvipastoris representavam $25 \%$.

Trabalho similar foi desenvolvido por Valle Júnior et al. (2010) na bacia do Rio Tijuco, município de Ituiutaba, Minas Gerais. Neste estudo os autores avaliaram as APPs de cursos d'água baseado nas definições do Código Florestal de 1965. 0s resultados obtidos revelaram que as atividades agrossilvipastoris ocupavam, aproximadamente, $76 \%$ da área total da bacia, enquanto a vegetação nativa distribuía-se ao longo de 21\% da área. As APPs de curso d'água totalizaram 3,85\%, sendo que desta área aproximadamente 50\% não atendia à legislação, ou seja, não possuía cobertura florestal nativa.

De forma a contribuir com os resultados obtidos considerou-se o trabalho realizado por Okuyama et al. (2012) no estado do Paraná, em que foi avaliada a adequação de 147 propriedades rurais de base familiar ao Código Florestal de 1965. Os resultados indicam que o somatório das APPs de todas as propriedades rurais equivalia a 20,4\% da área total de estudo, sendo que destes 15,5\% possuem vegetação nativa, enquanto 4,9\% exigiam recomposição.

0 panorama descrito nos estudos citados indica variações no estado de conservação das APPs assim como no uso e ocupação do solo nestas áreas. Deve-se considerar que cada área de estudo representa as características particulares, destacando ainda que as áreas em que foram desenvolvidos os estudos são significativamente maiores que a propriedade em análise, o que contribui para mescla de áreas em níveis de conservação e exploração distintos.

Apesar de se avaliar no presente estudo apenas uma propriedade rural, avaliando-se os resultados obtidos com aqueles alcançados nos estudos citados, verifica-se a tendência geral de inadequação das áreas rurais aos parâmetros definidos no Código Florestal Federal.

Constatadas as inadequações no que se refere à vegetação nativa em APPs de curso d'água e nascente, verifica-se a oportunidade de readequação destas áreas ao Novo Código Florestal Federal. A lei prevê a readequação das propriedades registradas no CAR através do Programa de Regularização Ambiental. De acordo com a legislação a recomposição mínima nas APPs, indicada no mapa da Figura 5, poderá ser implementada por meio dos seguintes métodos: 
condução de regeneração natural de espécies nativas; plantio de espécies nativas; plantio de espécies nativas conjugado com a condução da regeneração natural de espécies nativas; plantio intercalado de espécies lenhosas, perenes ou de ciclo longo, exóticas com nativas de ocorrência regional, em até 50\% da área total a ser recomposta - no caso propriedades com até 4 módulos fiscais (BRASIL, 2012).

Assim, analisando as particularidades da propriedade rural e os dispositivos previstos no Novo Código Florestal, podem ser consideradas algumas situações de recomposição e manejo das atividades a fim de conciliar os aspectos ecológico e econômico.

A recomposição da vegetação nativa poderá ser promovida conjugando a condução da regeneração natural com o plantio de espécies nativas escassas ou dizimadas na região, buscando-se a diversificação de espécies. Nos casos das APPs ainda sujeitas a pisoteio de animais deve-se realizar o cercamento das áreas e nos casos em que for inevitável a transposição do curso d'água pelo gado recomenda-se a instalação de pequenas passagens suspensas para evitar a erosão das margens e degradação do recurso hídrico.

Nos pontos de dessedentação dos animais recomenda-se a implantação de bebedouros d’água com instalação apropriada. Na Figura 6 é exemplificado degradação das margens e leito de um curso d'água na área de estudo, consequências de um bebedouro sem a devida configuração adequado ao uso pelos animais.

Devido ao fato de não ser prevista em lei a recomposição vegetal nas AUR e as boas práticas agronômicas citadas no Novo Código Florestal variarem em relação a fatores como, uso do solo, estabilidade natural do terreno, relevo, clima, disponibilidade tecnológica e outros, recomenda-se a divisão da área de pastagem em piquetes e a promoção do pastejo rotacionado, de forma a garantir a recuperação das pastagens e evitar exposição do solo. Em locais de inclinação mais acentuada e de difícil acesso ao gado sugere-se a formação de florestas com espécies nativas e exóticas favorecendo a interligação de fragmentos florestais. Ademais, destaca-se que, havendo disponibilidade de áreas e interesse do produtor em diversificar a produção, pode ser implantado o sistema silvipastoril, observando técnicas sustentáveis de conservação do solo e recursos hídricos, conforme exemplificado na Figura 7. 


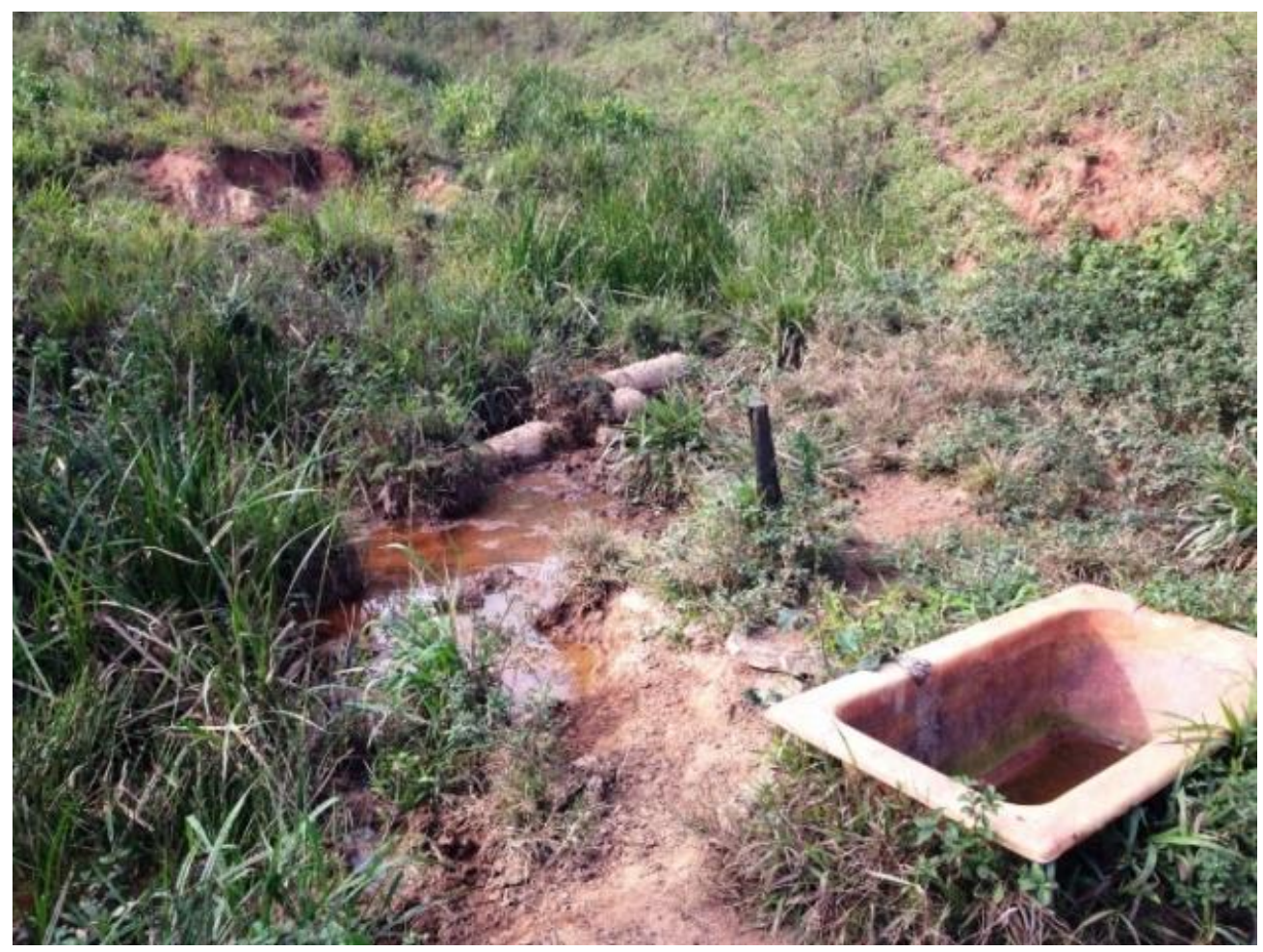

Figura 6. Bebedouro para dessedentação de animais desativado Fonte: 0s Autores, 2015.

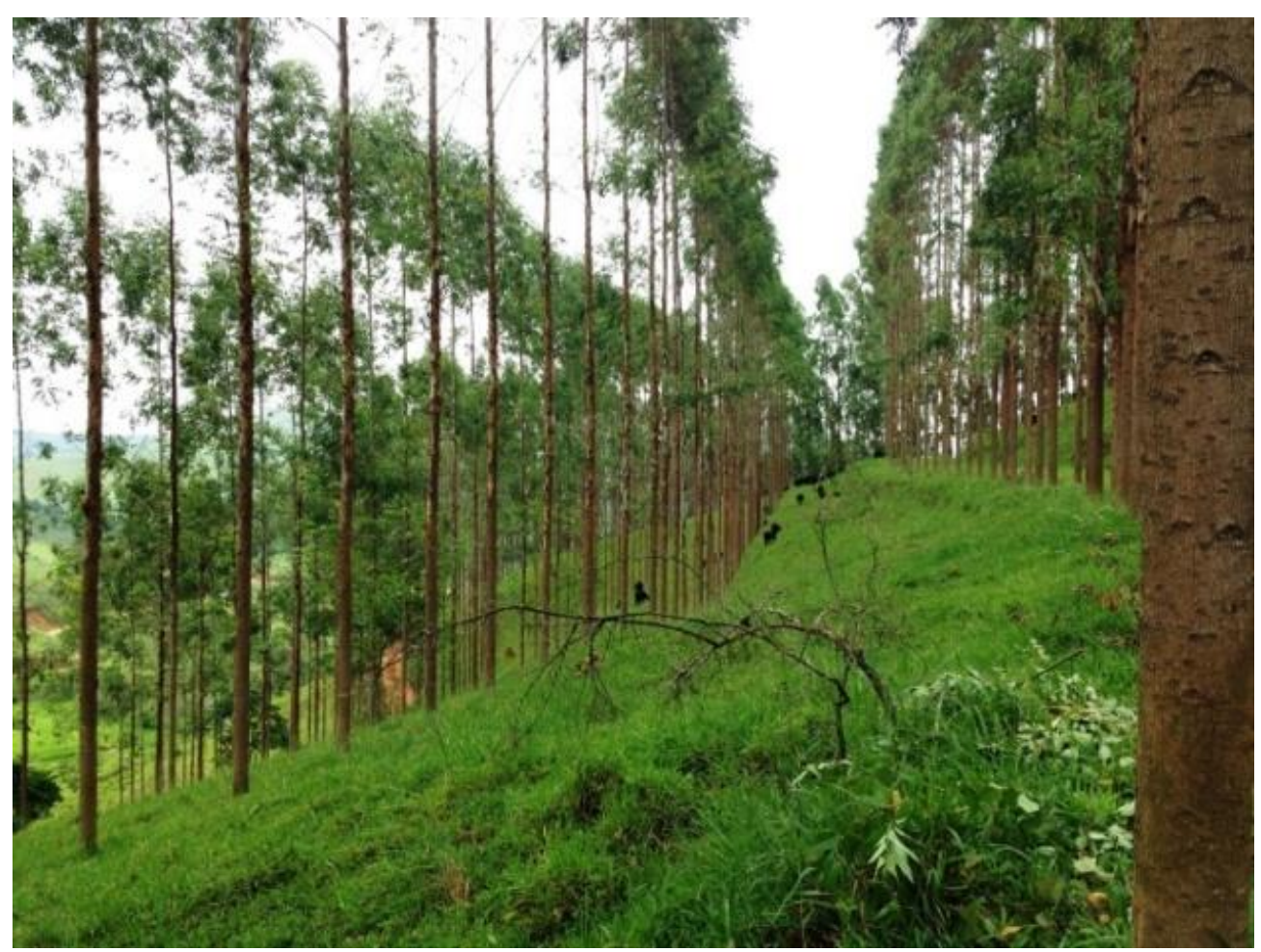

Figura 7. Exemplo de sistema silvipastoril implantado em uma propriedade rural da Zona da Mata Mineira Fonte: 0s Autores, 2015. 


\section{CONCLUSÃ0}

Diante do que foi apresentado no presente trabalho, pode-se concluir que, no caso do local do estudo, as imagens do RapidEye disponibilizadas pelo Ministério do Meio Ambiente para realização do Cadastro Ambiental Rural não proporcionaram qualidade suficiente para a identificação de algumas feições presentes no campo, incorrendo em erros consideráveis na delimitação tanto do perímetro do imóvel quanto na digitalização das feições ambientais do imóvel, enquanto as imagens disponibilizadas pelo Google Earth apresentaram-se satisfatórias, visto que permitem ao pesquisador reconhecer na imagem feições observadas em campo, tais como cercas, benfeitorias, corpos d'água, áreas de cultivo entre outras.

Na propriedade rural estudada estão presentes APPs de curso d'água e nascente, totalizando 19,42 ha. Apenas 3,92 ha de APPs estão cobertas por vegetação nativa, sendo obrigatória a recomposição de no mínimo 6,85 ha para adequação da propriedade ao Código Florestal Federal.

Para a recomposição da área mínima em APP são propostas medidas de manejo e ocupação do solo baseadas nas particularidades da propriedade rural e em técnicas de conservação e sustentabilidade do meio físico ambiental.

\section{REFERÊNCIAS BIBLIOGRÁFICAS}

BRASIL. Lei $\mathrm{n}^{\circ} \mathbf{1 2 . 6 5 1}$, de 25 de maio de 2012. Dispõe sobre a proteção da vegetação nativa; altera as Leis n ${ }^{\circ} \mathrm{s} 6.938$, de 31 de agosto de 1981, 9.393, de 19 de dezembro de 1996, e 11.428, de 22 de dezembro de 2006; revoga as Leis $n^{\circ} \mathrm{s}$ 4.771, de 15 de setembro de 1965, e 7.754, de 14 de abril de 1989, e a Medida Provisória n ${ }^{\circ}$ 2.166-67, de 24 de agosto de 2001; e dá outras providências. Câmara dos Deputados, Brasília, DF, 25 mai. 2012.

CARVALHO, L. M. T.; SCOLFORO, J. R. S.; CAVALVANTI, H. C. Ocupação das Áreas Desflorestadas no Estado de Minas Gerais: Atores e Causas da Modificação do Uso do Solo. In: SIMPÓSI0 BRASILEIR0 DE SENSORIAMENT0 REMOT0, 14, 2009, Natal, Anais... Natal, 2009, INPE, p. 5687-5694.

CELIN FILHO, A. Caracterização física e uso de imagens de alta resolução para determinação do uso do solo em APP's na microbacia do Rio Preto - ES. São Mateus, 2014.

CPRM. Companhia de Pesquisa de Recursos Minerais. Mapa de Declividade em Percentual do Relevo Brasileiro. Brasília, 2013. Disponível em: 〈http://www.cprm.gov.br/publique/cgi/cgilua.exe/sys/start.htm?infoid=1481Gsid=9\#PTSEC-INS $>$ Acesso em: 17 abr. 2015.

FA0. Food and Agriculture Organization of the United Nations. State of the World's Forests, Roma, 2011.

FUNDAÇÃO SOS MATA ATLÂNTICA; INSTITUTO NACIONAL DE PESQUISAS ESPACIAIS. Atlas dos remanescentes Florestais da Mata Atlântica Período 2012 -2013, São Paulo, 2014. 
IBGE. Instituto Brasileiro de Geografia e Estatística. Mapa de Biomas e Vegetação. 2004. Disponível em: <http://www.ibge.gov.br/home/presidencia/noticias/21052004biomashtml.shtm〉. Acesso em: 20 mar. 2015.

IBGE. Instituto Brasileiro de Geografia e Estatística. Recomendações para levantamentos relativos estáticos - GPS. 2008.

INPE. Instituto Nacional de Pesquisas Espaciais. Projeto de Monitoramento do Desmatamento na Amazônia Legal por Satélites (PR0DES): taxas anuais do desmatamento - 1988 até 2014, São José dos Campos, 2015. Disponível em: 〈http://www.obt.inpe.br/prodes/prodes_1988_2014.htm〉. Acesso em: 15 mar. 2015.

NASCIMENTO, M. C. et al. Delimitação automática de áreas de preservação permanente (APP) e identificação de conflito de uso da terra na bacia hidrográfica do rio Alegre. In: Simpósio Brasileiro de Sensoriamento Remoto, 12 , 2005, Goiânia, Anais...Goiânia: INPE, 2005, p. 2289-2296.

OKUYAMA, K.K. et al. Adequação de propriedades rurais ao Código Florestal Brasileiro: Estudo de caso no estado do Paraná. Revista Brasileira de Engenharia Agrícola e Ambiental, Campina Grande, v.16, n.9, p.1015-1021, 2012.

OLIVEIRA, G.C.; FERNANDES FILHO, E.I. Metodologia para delimitação de APPs em topos de morros segundo o novo Código Florestal brasileiro utilizando sistemas de informação geográfica. In: SIMPÓSI0 BRASILEIR0 DE SENSORIAMENT0 REM0T0,16, 2013, Foz do Iguaçu, Anais...Foz do Iguaçu: INPE, 2013, p.4443 - 4450.

SANTOS, C. A.; MARTINS, M. I. F. P. 0. Análise e mapeamento do uso e ocupação do solo nas áreas de preservação permanente no município de Alfenas - MG. In: SEMINÁRIO LATINO AMERICANO DE GEOGRAFIA FÍSICA, 6, 2010, Coimbra, VI Seminário...Coimbra, 2010.

SANTOS, F. C. Desenvolvimento econômico, pobreza e desmatamento no Brasil: evidências empíricas para as regiões Sul e Sudeste nas décadas de 80 e 90. Rio de Janeiro, 2004.

VALLE JÚNIOR, R. F. et al. Diagnóstico das áreas de Preservação Permanente na bacia hidrográfica do Rio Tijuco, Ituiutaba - MG, utilizando tecnologia SIG. Revista Engenharia Agrícola, Jaboticabal, v. 30, n.3, p. 495-503, 2010.

YOUNG, C. E. F. Desmatamento e desemprego rural na Mata Atlântica. Floresta e Ambiente, Seropédica, v. 12, n. 2, p. 75-88, 2006.

ZANATA, J. M. Análise do uso e ocupação do solo nas áreas de preservação permanente da microbacia Ribeirão Bonito, apoiada em técnicas de geoprocessamento. Revista Geonorte, v.2, n.4, p. 1262-1272, 2012. 